\title{
DISCLAIMER
}

This report was ptepart as an account of wark sponsored by an agency of the United States United Siates Government nor any agency thereof, nor any of thejGovernment. Neither the United Slates Goves or implied, or assunes any legal liability or responsiemployees, makes any warranty, express or implied, or assumformation, apparatus, producl, or bility for the accuracy, completeness, or usefulness or any infor infringe privately owned rights. Reler. process disclosed, or represents that its use would nol infringe privately owned rights. Re trade name, trademark, ence herein to any specific commercial produch, process, or sectivarily constitule or imply its endorsement, recom-

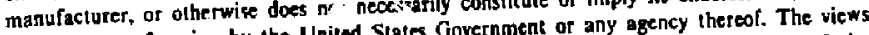
mendation, or favoring by the United States Uoven necessarily state or reflect those of the

and opinions of authors exptessed herein do nol

\section{Error Analysis of a New Asymmetric}

\section{Abel-Inversion Method}

\author{
Hyeon K. Park \\ Princeton Plasma Physics Laboratory, Princeton University \\ Princetori, NJ 08543
}

\begin{abstract}
Propagation of the various errors in a new asymmetric Abel-inversion method $^{1}$ is investigated. In order to provide a meaningful error analysis of the inversion process, both the effects of geometrical factors and measuremental errors are studied. The dominant source of uncertainty in the determination of local electron density is due to the spline fitting of the interferometric measurements with uneven spacings. The propagation of these ertors is highly spatially localized and heavily damped in this inversion method. The absolute range of error in the local electron density is $\pm 1.5 \times 10^{12} \mathrm{~cm}^{-3}$.
\end{abstract}




\section{Introduction}

The uncertainties in the determination of local electron density from chordal interferometric measurements in a tokamak plasma are dependent upon the propagation of errors in the inversion method. The sources of errots can be divided into uncertainties in the input data (measurements or fitted data) and the geometrical factor (path length). If the path length estimation is incorrect or the assumptions on the geometry are not realistic, the estimated errors in the inversion process are meaningless. A new asymmetric Abel-inversion method ${ }^{1}$ developed for the TFTR interferometry system ${ }^{2}$ has produced reliable inverted electron density profiles. A simultaneous estimation of flux geometry and local density allow calculation of various electron density and pressure parameters. ${ }^{3}$ In this payer, the detailed study of the propagation of errors in this method is presented. In Sec. II, the effects of uncertainties in the flux geometry used in this inversion method are examined in: detail. these include effects of magnetically determining the major radius $\left(R_{0}\right)$ and minor radius $\left(a_{0}\right)$, the radial dependence of the Shafranov shift, and the flux surface elongation. In Sec. III, the effect of boundary conditions and spline fitting of unevenly spaced interferometric measurements is examined for sariuus density profile shapes (e.g. hollow, parabolic and highly peaked profiles). The dominant source of error is the propagation of the fitting un. certainties in the inversion process. It is also notable that the errors in this intersion method are generally spatially localized where the uncertainty is 
large and the propagation of these errors are quickly damped. The asymmetries of the electron density on a flux surface within $r / a \leq 0.5$ are caused by this type of error. Within the estimated error, the electron density seems to be constant on a magnetic flux surface.

\section{Errors due to uncertainties in flux geometry}

The flux geometry used in this inversion method is approximated by employing the magnetically determined $R_{0}$ and $a_{0}$ which have small errors $15=27)$. Therefore. the variation of the inverted profiles due to these uncertainties in $R_{0}$ and $a_{0}$ is relatively small. Similarly, the error on the Shafranov shift and the surface elongation profile shapes are also a small contribution, as discussed in Ref. 1. Although, the uncertainties in the center of the Shafranov shift $\left(\varepsilon_{0}\right)$ do not effect the global shape of the inverted profile as shown in Fig. 3 in Ref. 1. asymmetries of the electron density on a fiux surface are very sensitive to this parameter in the inversion process. As demonstrated in Fig. 1, the $\epsilon_{0}$ determined self-consistently with the assumption that the asymmetry in the innermost flux surface is less than $5 \%$. provides the smallest values of asymmetry across the profile. In general, the errors due to the geometrical factors in this inversion method are not a significant factor. 


\section{Errors due to measurements and data prepara- tion}

The uncertainties in the input data to the inversion are classified in two categories; these are measuremental errors and errors due to data preparation. The errors due to various cross talk problems in an interferometer system are eliminated using a half wave technique. Among the measuremental errors, the systematic error is due to the slow motion of the interferometer structure during a discharge period. The range of this type of error is less than 110 th of a fringe (one fringe is equivalent to $1 \times 10^{15} \mathrm{~cm}^{-2}$ for a wave. length of $119 \mu \mathrm{m})$. This type of error can be easily corrected by adjusting the baseline. The other type of error is caused by the magnetic field effect on the lasers and the fast response of the structure. These errors are even smaller by a factor of two compared to the first type of error and the propagation of these errors in the inversion is negligible.

Uncertainties due to data preparation are mainly boundary estisnation and spline fitting errors. Since the outermost flux surface is very close to the jnner bumper limiter, the innermost boundary point is chosen to be a linear extrapolation of two measured points (the first and second data points from the inner belt limiter as shown in Fig. 2a). On the other hand, the outermost boundary point can be determined with a better accuracy, since the last measured point is beyond the scrape-off layer. In order to test the effects of boundary conditions, three line-integral density profiles are constructed using 
different inner boundary conditions as shown in Fig. 4a in Ref. 1. The three extrapolation points are: higher than the linear extrapolation value, zero density at the limiter position, and a linear extrapolation point. Since the geametry employed for the inversion is fixed, errors in the inverted profile are purely those in the density. The error propagation is suppressed very quickly as shown in Fig. 4b in Ref. 1. The linearly extrapolated results had the best agreement with the measurements made by Thomson scattering.

In the TFTR interferometry system, ${ }^{2}$ the line density profile is based rin a ten-channel measurement with uneven chord spacing, as shown in Fig. 2. is cubic spline fit is therefore introduced. Among the ten chords of the interferometry system, the greatest distance is between the 6 th $(268 \mathrm{~cm})$ and ith chord $(300 \mathrm{~cm})$ as shown in Fig. 2a. The effect of the spline fitting of uneven chords can easily be demonstrated here. First, the data are prepared with a standard cubic spline fit of the ten chordal measurements and the inversion is performed. The inverted result will serve as a reference. Second, the line-integral density of the spline-fitted data at $285 \mathrm{~cm}$ is perturbed by adding and substracting $1 \times 10^{14} \mathrm{~cm}^{-2}$. Including the perturbed data points, the data are re-splined and inverted. These results are compared with the reference profile. In order to test the sensitivity of the spline fitting to the shape of the profile. three different types of profiles are tested; these are ohmic. hollow. and highly shifted and peaked profiles.

In an ohmic plasma where the Shafranov shift is relatively small ( $\epsilon_{0} \leq$ $10 \mathrm{~cm}$ ) and the shape is parabolic, one might expect that the spline fitting 
would be reasonable. As shown in Fig. 2b, the perturbation made at 285 $\mathrm{cm}$ is confined within half of the profile. The deviation from the reference profile shown in this figure is as expected. If the electron density is nearly constant on a magnetic flux surface, the reference profile is the best results. A similar example is given for a hollow profile in Fig. 3a. It is notable that if one of the peaks of the hollow profile is located near $285 \mathrm{~cm}$ where the perturbation is made, the reference profile may underestimate one side of the hollowness based on the symmetry argument. Since the geometry is similar to the vhmic case (small $\epsilon_{0}$ ), the propagation of errors is expected to he :inular 10 the uhmic case. For the a highly peaked profile with a large Shafranor shift ( $\epsilon_{0}$ is up to $30 \mathrm{~cm}$ ), the propagation of the perturbation is no longer confined within half of the profile as shown in Fig. 3b.

Simlilar tests were also made throughout the profile with the same perturbation made at $285 \mathrm{~cm}$. The absolute error and its propagation were smaller than the results demonstrated at $285 \mathrm{~cm}$. Together with the assumption of symmetry of the electron density on a flux surface, the range of absolute uncertainty in local electron density determined with this inversion method is $\pm 1.5 \times 10^{12} \mathrm{~cm}^{-3}$.

\section{Summary}

In this paper, the error analysis of a new asymmetric Abel-inversion method is presented. The major uncertainties in inverted profiles are due 
to spline fitting of uneven chordal measurements. Propagation of the errors are heavily damped and localized where the perturbation is made. The range of absolute error in an inverted electron density is $\pm 1.5 \times 10^{12} \mathrm{~cm}^{-3}$.

\section{Acknowledgments}

This work was supported by U.S. Department of Energy contract No. DE-ACO2-76-CHO-3073. 


\section{References}

${ }^{1}$ Hyeon K. Park, (1989). Plasma Phøs. and Controlled Fusion, 31, 2035-2046.

${ }^{2}$ D.K. Mansfield, H.K. Park, L.C. Johnson, H.M. Anderson, R. Chouinard, V.S. Foote, C.H. Ma, and B.J. Clifton (1987). Appl. Optics, $\underline{15}, 4469$.

${ }^{3}$ H.K. Park, R.J. Goldston, and G. Taylor, in Proceedings of 4th International Symposium on Laser-Aided Plasma Diagnostics, (1989), 17

${ }^{4}$ H.K. Park. D.K. Mansfield, L.C. Johnson, and C.H. Ma, in Proceedings of SPIE $\underline{78 \mathrm{i}} \cdot(198 \mathrm{i}) .110$. 


\section{Figures}

FIG. 1. Electron density asymmetry factor $(\xi)$ as a function of the normalized radius for three different values of Shafranov shift center $\left(\epsilon_{0}=22\right.$ $\mathrm{cm}, 26 \mathrm{~cm}$ and $30 \mathrm{~cm}$ ). All other parameters are kept cunstant in the inversion process.

FIG. 2. (a) Example of the spline fitting for line-integrated electron density profile for an ohmic discharge and arrangement of interferometric chords in TFTR. (b) The inverted profile of (a) is compared with the inverted profiles of perturbed line integral density at $285 \mathrm{~cm}$.

FIG. 3. The inverted profile without perturbation is compared with profiles of perturbed line integral density at $285 \mathrm{~cm}$ for difierent types of the profiie shapes. (a) Hollow profile (b) Highly peaked and shifted profile. 


\section{tonnoly}

(D/p) onpay paxtewon

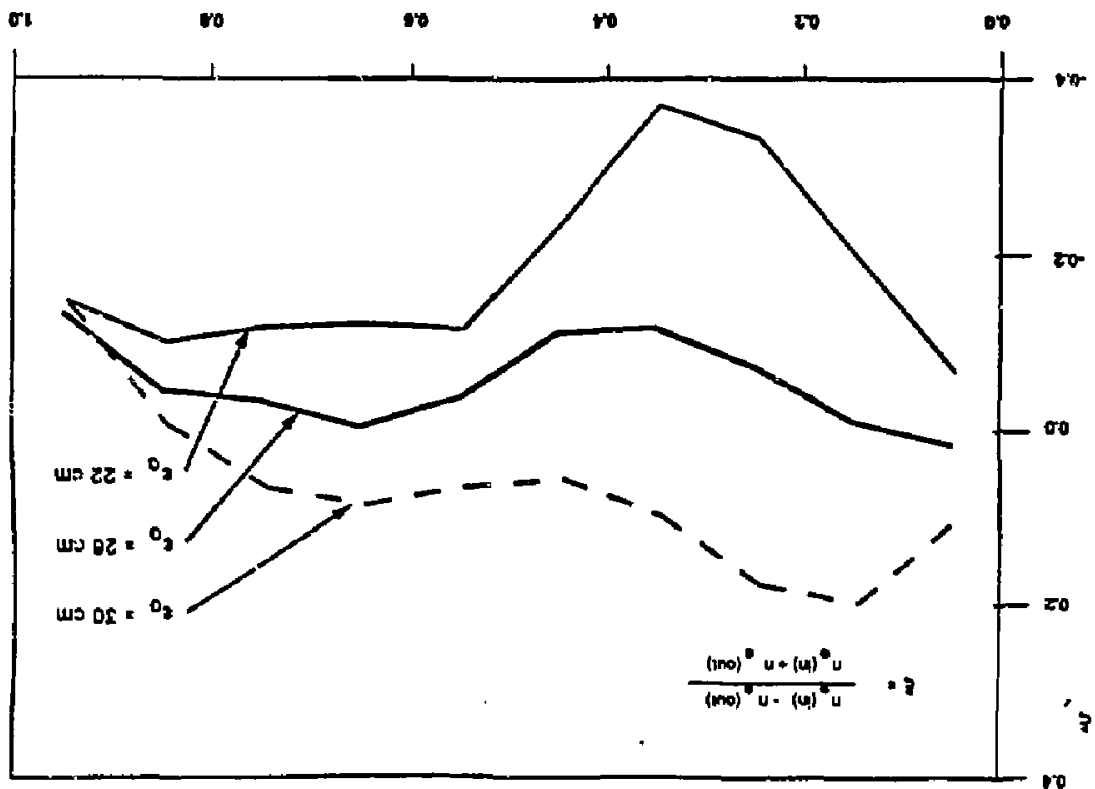




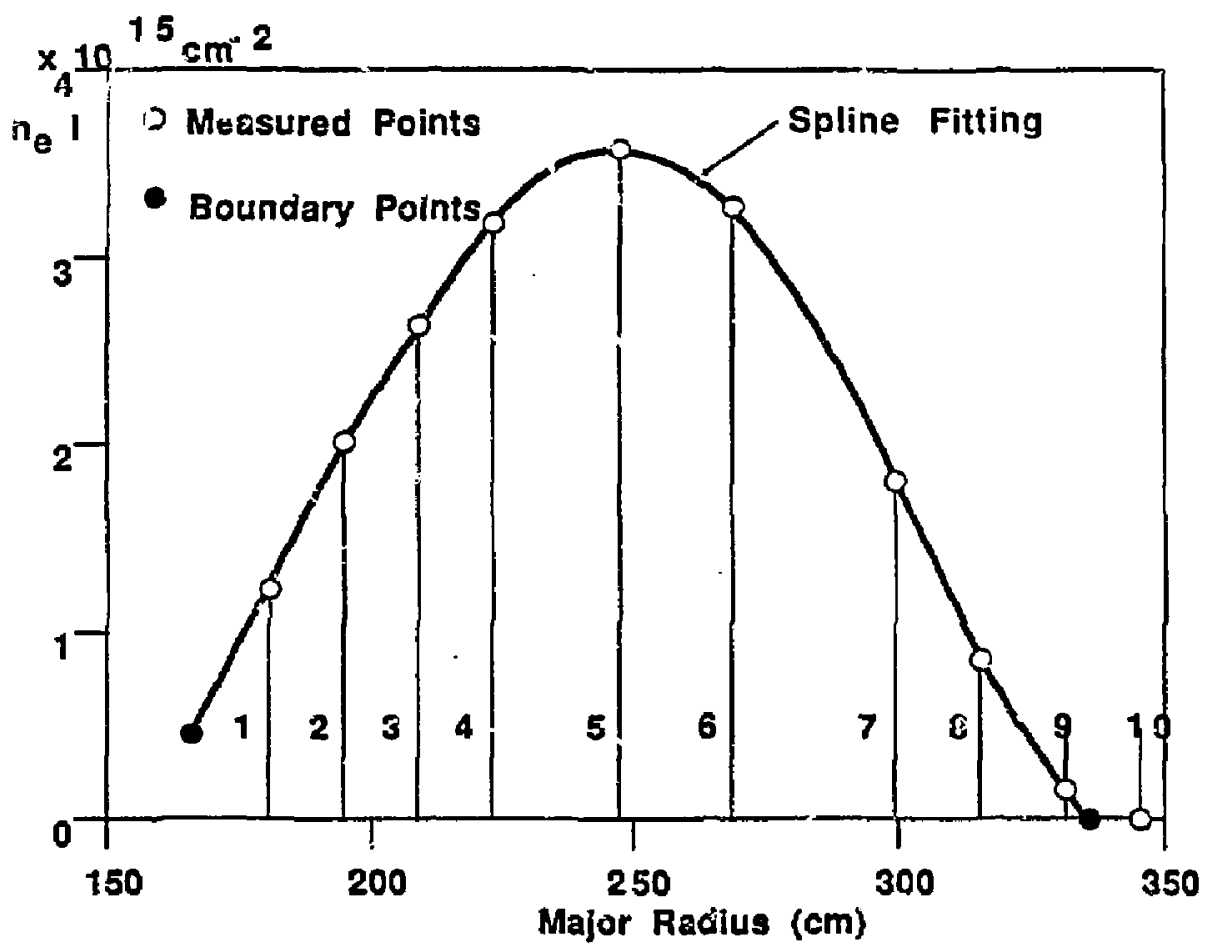

Figure 2a 


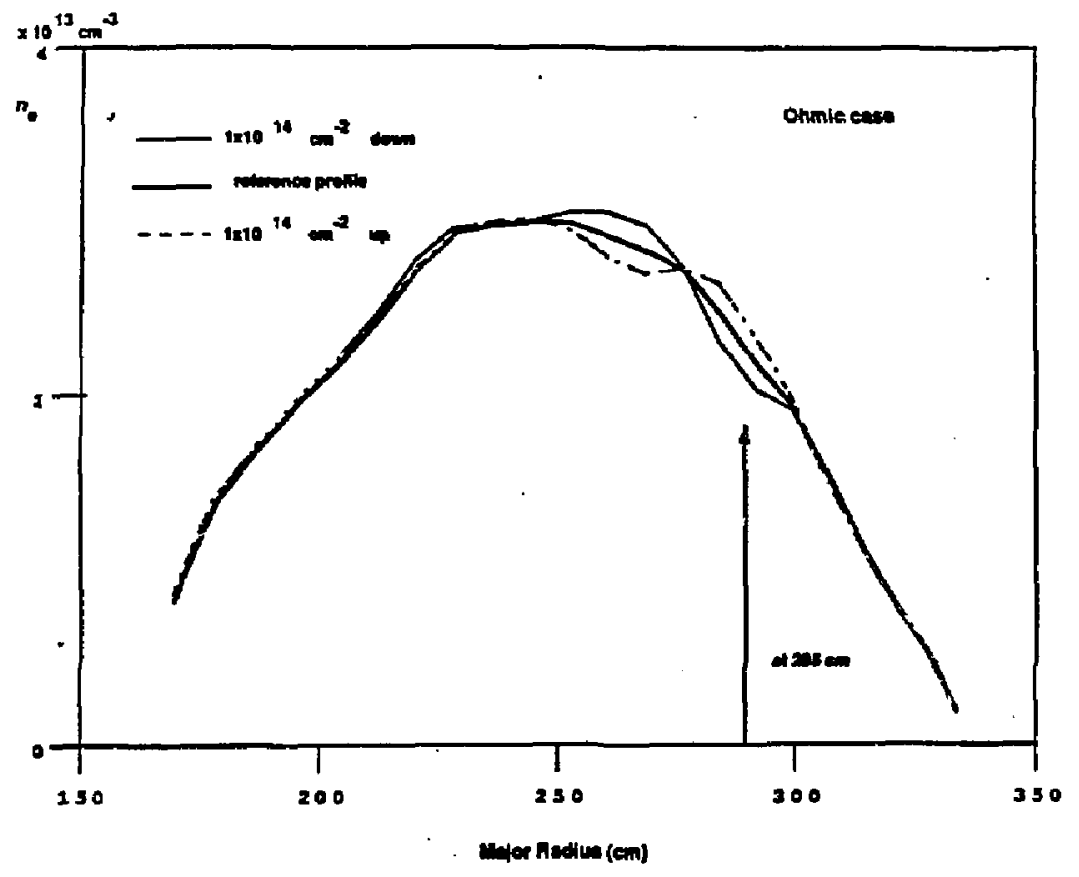

Flgure 2b 

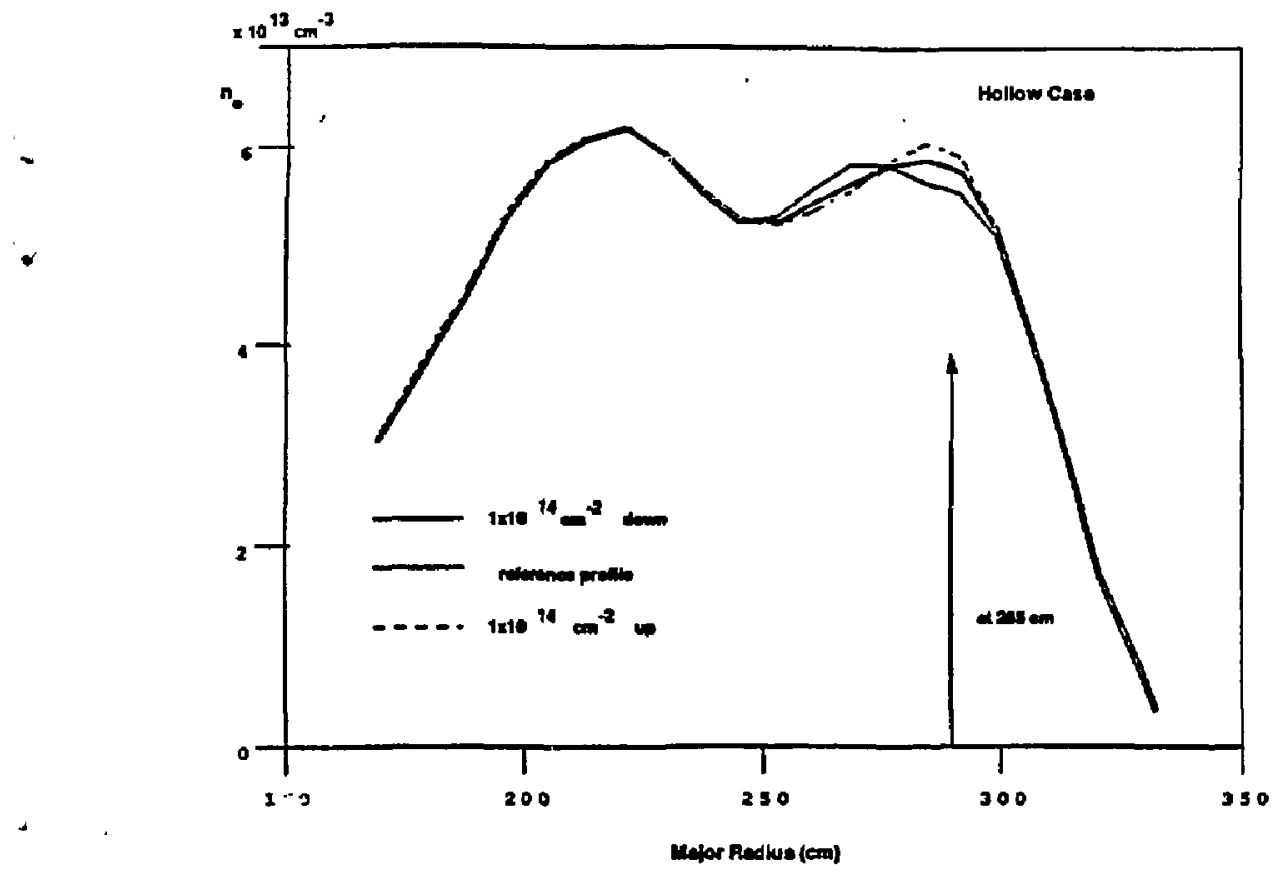

Figure 32 


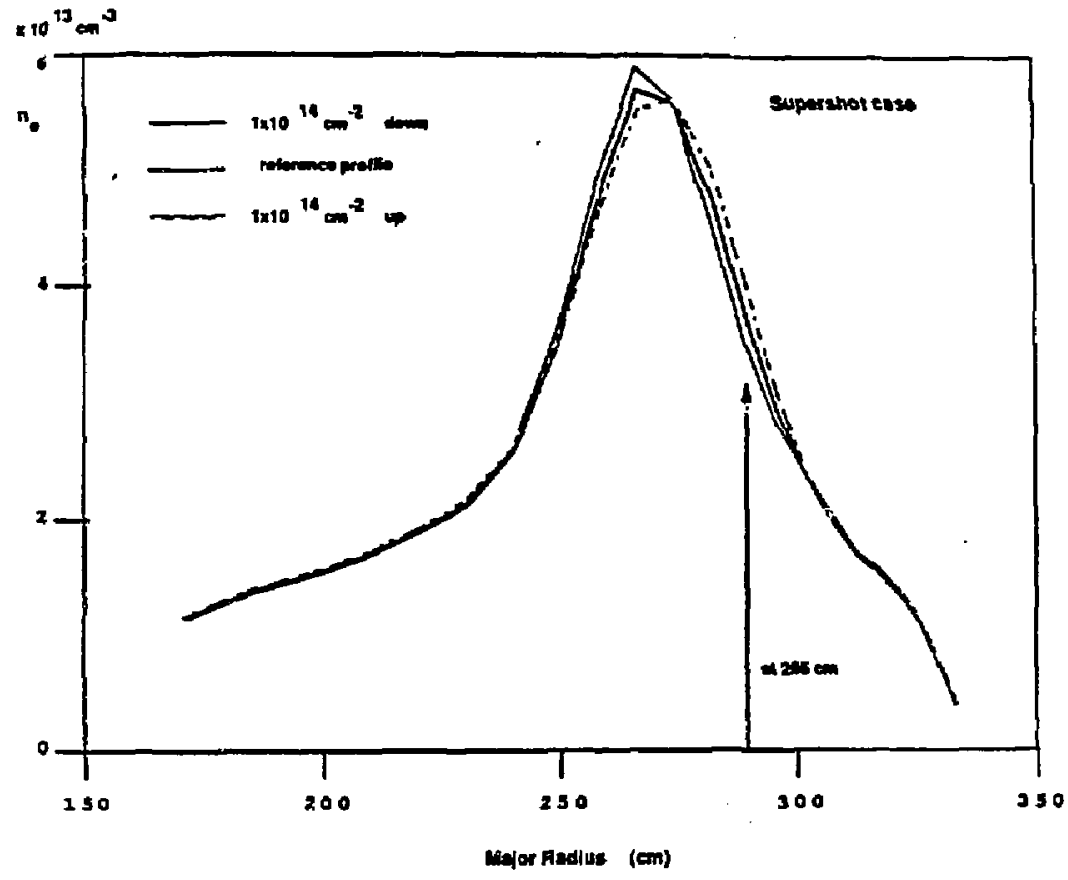

Figure 36 
Or. F. Paoloni, Univ. of Wollongong, AUSTaALA

Prof. M.H. Enemen, Univ. of Sydher, AUSTRALA

Plawn Riaench Lob. Austrien Mat UniY.. AUSTRALA

Prot, I.A. Jones, Flinders Univ, AUSTRAUA

Prof, F. Cap, Inst, lor Theoreticed Phyica, AUSTRIA

Prol. M. Heindler, Instiut for Theoratieche Physit, AUSTRIA

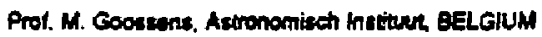

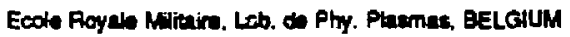

Commituion-Europeen, DG. XIl-Fusion Prog., BELGIUM

Prot. R. Boucique Ajksuniveritcit Gent, BELGIUM

Dr. P.H. Saknakn, Instituto Fiaica, BPazlL

Instituto De Pecquirus Esposiais-INPE, BRAZL.

Doouments Cfice, Atomic Energy of Cenede LAd. CANADA

Dr. M.P. Bechynekj, MPB Technologies, Ine. CANADA

Dr. H.M. Skerygard, Uriv, of Sackutehwmen, CANADA

Frol. J. Teichmenn. Univ, of Momted, CANADA

Prol. S.R. Srumivasen, Univ. of Calger. CANADA

PTof. T.W. Jomaton, INFS-Energi, CANADA

Dr. R. Bolion, Centre carndien de husion megnitiqua, CANADA

D. C.R. Lame., Univ. of Aborta, CANAOA

Dr. P. Luece, Kommakno Uniwazita, CZECHOSLOVAKLA

The Lerevien, Culhem Luborasy, ENCLAND

Ltrry. Ast, Rutrectord Apowion Lboratory, ENCLAND

Ars. SA. Hubtinacn, JET Libray, ENGLAND

P. Mthonen, Univ. of Helindd, FINLAND

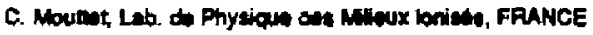

J. Fudat, CENICADARACHE - Eat sos, FANMCE

Hts. C. Ainni, Univ. of lomine, GREECE

D. T. Murd, Neadumy Eibliegraphie Ser., HONG KONG

Preprint Librey. Hungarien Acadomy of Sei., HUNGARY

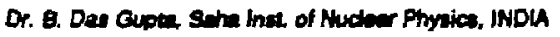

Dr. P. Kaw, fmet for Piveme Feasexh, INDIA

Dr. P. Rocenaw, lared hat of Tectnology, SRAEL

Librerien, Imimationed Conter tor Thwo Phytica, ITALY

Whe C. Do Paio, Aleociaziono EURATOAENEA ITALY

Dr. G. Groseo, istitus of Fitien del Plama, ITALY

Dr. H. Yemalo, Toshibn Pei D Dowl Cener, JAPAN

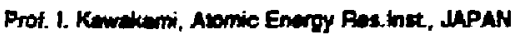

Prof. K. Nithikemt, Hirostime Univ., JAPAN
Obector, Jepan Alomic Eneroy Reveurch lna., JAPAN

Prof. S. Itoh, Kyuthu Univ., JAPAN

Data and Planning Cerner, Nesoya Univ., JAPAN

Prof. S. Tanaka, Kyoto Univ., JAPAN

Librery. Kyolo Urily., HAPAN

Prol. N. Inowe, Univ. of Tokyo, JAPAN

S. Mori, Technicel Advier, MAEAI. JAPAN

O. Mitur, Kumenoto inst of Tectnology. JAPAN

H. Jorg, Kone Advanced Enargy Roseurch Inst., KOREA

Prot. D.I. Choi, Tho Kone Adv. Inst of Sal. a Tech., KOREA

Prot. 8.S. Lim. Univ. of Watrob. NEW ZEALAND

inat of Piam Phyics, PEOPLES REPUBLIC Of CHINA

Libreion, Inat of Phytas, PEOPLES REPUBUIC OF CHINA

Libry. Ttinghu Univ. PEOPLE'S REPUBLC OF CHINA

2 U. S.W. Inst Phycict, PEOPLE'S REPUBUC OF CHINA

Prof. J.A.C. Cubre, hettulo Superior Teanico, PORTUGAL

D. O. Perte, AL I CUzA Unir., ROMANLA

Dr. J. da Viners. Fution Sudies, MEC. S. AFRICA

Prof. M. A. Heltberg, Univ. of Nates, S. AFAlCA

C.IEMA.T, Fution Oivioion Libry, SPAIM

Dr. L Gento, Univ, of UAFEA, SWEDEN

Lorey, floyd inst of Technobay, SWEDEN

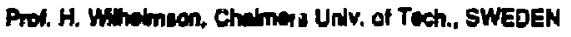

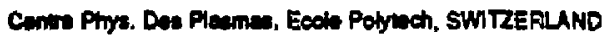

Eiblictheak, hat. Voor Plann-Fyica, THE NETHERLANDS

M. Ounot, Vice Chaimen, Midle East Tech. Uniw., TURKEY

D. D.D. Ryutov, Siberien Bunch of Mesdimy of Sa, USSR

Dr. GA. Elienr, Kurctator Inot, USSA

Librerion, The Ukr.sSA Academy of Sciunces, USSA

D. LM. Kovizenoyk. Inal of Generd Phyaics, USSR

Kemionectungsenlege Cmbty, Zentrabibiothek, W. GEAMANY

Eibtiothet, Inte. For Plesmutorechung. W. GERMANY

Prof. K Schindx, Puthe-Univerita Bachum, W. GERMANY

Dr. F. Wegner, (ASOEX), Max-Plenck-Inetitut, W. GERMANY

Libraien, Max.Planck-Instiut, W. GEFMANY

Prot. R.K Jener. Ind. of Physics, YUCOSLAVIA

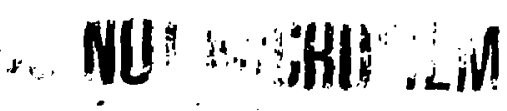

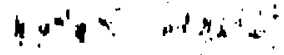

